\title{
Professores iniciantes ensinando História: dilemas de aula e desafios da formação
}

\author{
Beginner teachers teaching History: \\ class dilemmas and formation challenges
}

Flávia Eloisa Caimi*

\section{RESUMo}

A maneira como os professores aprendem em contextos de formação e atuação tem constituído tema central nos debates sobre qualidade da educação e melhoria do ensino. Diante disso, este estudo segue o propósito de investigar os processos de aprendizagem profissional de acadêmicos em situação de estágio curricular supervisionado, na licenciatura em História, com vistas a identificar de que conhecimentos e estratégias se valem esses sujeitos para dar conta das demandas e desafios que se colocam no contexto de iniciação à docência. Nos limites deste artigo são analisados os registros de aula de uma acadêmica cujo estágio realizou-se na última série do ensino fundamental. Além da análise dos registros (planejamento, atividades, memórias de aula e memorial final), desenvolveu-se observação de aulas e entrevista não estruturada.

Palavras-chave: História; estágio; aprendizagem profissional.

\section{Abstract}

The way the teachers learn in formation and acting contexts has been the core issue in the debates about the education quality and education improvement. From this point, this study's purpose is to investigate the academic's professional learning processes in History graduation overseen internship situations, aiming to identify which knowledge and strategies these students use to deal with the demands and challenges that appear in the beginning of this teaching context. Within the limits of this study, the class records made by a student whose internship has been done in the last grade of elementary school are analyzed. Besides the records analysis (planning, activities, class memories and final memory), a class observation and a non-structured interview have been made.

Keywords: History; supervised training; professional learning.

$\mathrm{Na}$ literatura educacional tem-se dedicado especial atenção aos saberes e competências necessários à atuação docente. Diversos autores ${ }^{1}$ vêm procuran-

\footnotetext{
* Faculdade de Educação, Universidade de Passo Fundo (UPF). Campus I, São José. 99001-970 Passo Fundo - RS - Brasil. caimi@upf.br
} 
do demonstrar a importância de prestar atenção aos modos como os professores transformam os conhecimentos que possuem em saberes ensináveis e compreensíveis para os seus alunos. Ainda, apontam um conjunto de saberes necessários à docência, que dizem respeito, grosso modo, aos saberes da experiência, aos conhecimentos/conteúdos da área específica, aos saberes didático-pedagógicos, aos saberes curriculares e aos conhecimentos dos contextos educativos, dentre outros.

Ao nos debruçarmos sobre o contexto formativo da atividade de Prática de Ensino e Estágios na Licenciatura em História, interessou-nos investigar como os professorandos ${ }^{2}$ estão constituindo sua aprendizagem profissional, no intuito de identificar que elementos cognitivos e contextuais caracterizam seu desempenho competente na sala de aula. O que entendemos por desempenho competente, neste estudo, não é a capacidade de dar todas as respostas ou de solucionar todos os problemas da aula, e sim a disposição de identificar quais dificuldades se apresentam em dada situação; de reconhecer que limitações e potencialidades têm para enfrentá-la; de perceber o que sabem e o que lhes falta saber para enfrentar os dilemas que surgem no cotidiano da sala de aula, enfim, um conjunto de habilidades que Bransford, Brown e Cocking (2007) denominam 'competência adaptativa', conceito associado ao de metacognição, consubstanciado na tarefa de avaliar o próprio progresso, identificar e perseguir, de modo contínuo e sistemático, novos objetivos de aprendizagem.

Frente às inquietações que movem nossa prática de formadores de professores de História na licenciatura, temos buscado compreender como as trajetórias de formação dos sujeitos convergem para práticas qualificadas de ensinar-aprender em situação de estágio supervisionado. Dentre as principais indagações, destacamos: a) De que conhecimentos, instrumentos cognitivos, estratégias, recursos e características pessoais se valem esses sujeitos na medida em que necessitam mobilizar tais aportes para ensinar outros? b) Quais as mediações e/ou estratégias de aprendizagem implicadas na apropriação/construção dos aportes necessários para viabilizar uma prática de ensino que atenda qualificadamente às demandas da aula, resultando em desempenho competente? c) Como reagem os sujeitos frente a situações que requerem a organização do conhecimento, a compreensão e resolução de problemas?

Para desenvolver o estudo, acompanhamos a trajetória de formação acadêmica de um grupo integrado por cinco sujeitos previamente identificados 
como estudantes destacados na licenciatura em História, cujo desempenho docente sobressai-se em relação à média da turma, em situação de estágio supervisionado, apesar de não possuírem nenhuma experiência docente até o momento de realizar tal prática na licenciatura. Do ponto de vista metodológico, foram adotadas as seguintes estratégias: a) observação de aulas e acompanhamento sistemático das suas práticas de estágio; b) coleta e análise de registros de aula produzidos pelos estagiários, tais como planos, atividades, memórias; c) entrevistas para a discussão de situações de aula, buscando identificar como enfrentam os 'dilemas práticos`3 da sua iniciação à docência.

No recorte definido para este texto, analisamos os registros formalizados nas memórias de aula ${ }^{4}$ de uma acadêmica integrante desse grupo-sujeito que realizou o estágio na disciplina de História no segundo semestre de 2011 com uma turma de $8^{\text {a }}$ série em escola da rede pública estadual. Na primeira parte do texto trazemos alguns pressupostos teóricos que orientam a proposta de formação que desenvolvemos na Prática de Ensino. Na segunda parte, dialogamos com os registros de aula da acadêmica de História em situação de estágio curricular supervisionado, buscando analisar as estratégias metacognitivas mobilizadas por ela em seu percurso de aprendizagem e atuação inicial na docência.

\section{APrendizAgem PROFISSIONAL E METACOGNIÇÃO: ALGUNS PRESSUPOSTOS ORIENTADORES DA FORMAÇÃO DE PROFESSORES}

A aprendizagem profissional do professor vem sendo entendida, na literatura educacional, ${ }^{5}$ como um processo complexo e contínuo, marcado por descontinuidades e oscilações. Aprender a/na profissão docente vai muito além de dominar conteúdos e estratégias de ensino, conforme preconizado pelo modelo da racionalidade técnica. Antes, significa atuar em contextos complexos e singulares, como o cotidiano da sala de aula, que exigem soluções possíveis e adequadas (e também originais e criativas) para lidar com imprevistos e incertezas.

Nesse sentido, tanto a experiência pessoal quanto a prática profissional são fontes importantes de aprendizagem docente, na medida em que o professor carrega consigo um conjunto de sistemas conceituais, crenças e juízos que orientam sua ação cotidiana e tendem a não se modificar tão facilmente frente 
a novos princípios e valores. Da mesma forma, a prática profissional pode contribuir para gerar, validar ou recusar determinados tipos de saberes, integrando-os ou alijando-os no/do dia a dia profissional.

Com Fernando Hernández compartilhamos a ideia de que a aprendizagem do professor, realizada em situações diversas de formação, manifesta-se em seus atos, que são, por sua vez, reveladores das aprendizagens que se converteram em representações pessoais da docência. Para esse autor, a aprendizagem profissional está relacionada com a capacidade de transferência e generalização do aprendizado, pois "alguém aprende quando está em condições de transferir a uma nova situação (por exemplo, à prática docente) o que conheceu em uma situação de formação, seja de maneira institucionalizada, nas trocas com os colegas, em situações não formais e em experiências da vida diária". ${ }^{6}$

Na mesma direção, Bransford, Brown e Cocking consideram que os professores aprendem a ensinar de diversas maneiras e em diferentes situações, tais como: a) aprendem com a própria prática em sala de aula, na reação dos seus alunos, nos sucessos e insucessos cotidianos; b) aprendem ao interagir com outros professores, em situações informais na escola ou em situações de formação continuada no âmbito escolar; c) aprendem com os educadores de professores em suas escolas, nos programas de estágio, de iniciação à docência, nos cursos de aperfeiçoamento; d) aprendem em programas de pós-graduação, nos processos institucionais de educação continuada, em nível lato e/ou stricto sensu; e) por fim, aprendem sobre ensino fora do seu trabalho profissional formal, nos papéis de pais e nos trabalhos voluntários com crianças e jovens em suas comunidades, dentre outros.

Em virtude da imprevisibilidade do contexto da sala de aula, é fundamental que os professores tenham planos de trabalho com objetivos claros e mantenham-se vigilantes sobre as ações e reações que os percursos da aula suscitam, além de exercerem atitude reflexiva na/sobre a docência. Assim, numa pesquisa que busca investigar em que medida e de que forma os processos formativos incidem sobre a aprendizagem profissional dos professores e contribuem para a qualificação da sua atuação em situações de ensino, voltamos nossa atenção também para o conceito de metacognição, no intuito de compreender os aspectos relacionados à autorregulação e à tomada de consciência da ação pedagógica diante dos dilemas da sala de aula vivenciados pelos estagiários. 
As pesquisas acerca da metacognição, segundo Fávero e Machado, ${ }^{7}$ estão diretamente relacionadas aos estudos sobre regulações, tomada de consciência e abstração refletida desenvolvidos por Jean Piaget, não obstante verificarmos que, ao longo de sua obra, esse autor não abordou de maneira explícita o conceito de metacognição com essa formulação. Com base nos estudos publicados por pesquisadores anglo-saxões, Fávero ${ }^{8}$ esclarece que o termo metacognição tem sido empregado para referir os conhecimentos que os indivíduos possuem sobre seus processos de pensamento, bem como para designar o controle que exercem sobre seus processos cognitivos. Citando Flavell (apud Fávero, 2005, p.288), a autora apresenta a seguinte definição para o termo:

A metacognição se refere ao conhecimento do sujeito dos seus próprios processos cognitivos, dos seus produtos e de tudo o que se relaciona a isso ... A metacognição diz respeito ao controle (monitoramento) ativo, à resultante regulação ou orquestração desses processos em função dos objetos cognitivos ou dos dados sobre os quais eles se referem, habitualmente, para alcançar um objetivo concreto.

Fávero e Machado apontam alguns consensos existentes entre os pesquisadores do campo da metacognição sobre os elementos que caracterizam tal categoria, assim sumarizados: 1) o termo contempla tanto a dimensão dos conhecimentos quanto a das regulações, a primeira referindo-se a pessoas, tarefas e estratégias, que são as representações na memória a longo termo, e a segunda dizendo respeito à tomada de consciência dos processos cognitivos em ação; 2) essas duas dimensões se distinguem por seus objetos, estando, no entanto, em contínua interação numa instância comum de construção; 3) a par da dificuldade de definir fronteiras entre cognição e metacognição, autores procuram distingui-las caracterizando a cognição segundo os aspectos conceituais e estruturais do desenvolvimento em geral, ao passo que a metacognição engloba "as regulações funcionais, ativadas segundo graus variados de consciência numa situação de aprendizagem”.

De acordo com Figueira, "indivíduos com competências metacognitivas bem desenvolvidas compreendem os objectivos das tarefas, planificam a sua execução, são capazes de aplicar e alterar, conscientemente, estratégias executivas, bem como avaliar o seu próprio processo de execução". ${ }^{9}$ Acredita-se que a prática metacognitiva possa colaborar na qualidade e eficácia da aprendizagem, especialmente nos aspectos de transferência e generalização, na medida 
em que possibilita reconhecer e avaliar dificuldades na execução de tarefas; produzir inferências sobre os saberes já apropriados e identificar os saberes ainda não apropriados; utilizar estratégias para organizar e mobilizar seus conhecimentos no sentido de resolver problemas; enfim, favorece a autorregulação, a autonomia e o aprender a aprender.

\section{A PRÁTICA DO ESTÁGIO SUPERVISIONADO SOB O SUPORTE DE ESTRATÉGIAS METACOGNITIVAS}

Ao chegar aos semestres finais de um curso de licenciatura, na iminência de entrar em sala de aula no papel de professores, os acadêmicos já vivenciaram incontáveis experiências na condição de alunos, ao longo de aproximadamente 15 anos frequentando os bancos escolares. Em virtude dessa trajetória, conseguem identificar e exprimir a essência do que é ser professor, reconhecer em que consiste um bom (ou um insuficiente) trabalho docente, indicar as falhas e os acertos dos professores no exercício da sua função. Essas representações do trabalho docente incidem, em certa medida, sobre suas escolhas, decisões e ações, no momento de assumir a tarefa de ensinar, ainda que como orientações intuitivas, sem os referenciais teóricos e o domínio técnico necessário para entendê-las e operá-las com autonomia.

Nosso propósito, nesta parte do estudo, é identificar algumas estratégias metacognitivas mobilizadas em situação de estágio curricular supervisionado, no sentido de compreender como a estagiária em questão lida com os dilemas, situações de emergência e incerteza da sala de aula, resultando no que se pode denominar desempenho competente. Reiteramos que esse desempenho competente não diz respeito, necessariamente, aos resultados quantitativos do ensino, mas ao modo como dá encaminhamento às dificuldades que vão se manifestando no cotidiano da sala de aula.

Posicionamo-nos contrariamente à imagem do professor como técnico, cujas competências devam ser treinadas, e recusamo-nos a conceber a aprendizagem profissional apenas como aquisição de conhecimentos. Assim, definimos os professores como profissionais cujas tarefas formativas compreendem a investigação e experimentação de novas ideias; a localização de si e dos alunos em contextos sociais, políticos e históricos mais amplos; a identificação 
e a exploração criativa de problemas; o confronto com discrepâncias e incongruências presentes no seu trabalho pedagógico.

Antes de prosseguir, cumpre-nos tratar brevemente do entendimento que adotamos neste estudo sobre o significado da escrita de 'memórias de aula'. Trata-se de um instrumento de reflexão que possibilita ampliar a capacidade de ver e de pensar a própria ação docente na interlocução com seus pares, assim caracterizado:

consiste na elaboração escrita que o estagiário realiza após o ato pedagógico (uma aula, uma reunião, um conselho de classe), buscando, pela escrita, objetivar a ação e o pensamento sobre a ação. Compõe-se da observação, do registro, da análise, da teorização e do redimensionamento da situação vivenciada. Distingue-se do mero registro descritivo dos acontecimentos, embora também possa contemplá-lo, visto que tenciona uma primeira elaboração teorizada da ação realizada e o levantamento de indicativos de redimensionamento do trabalho para uma nova intervenção. ${ }^{10}$

Os fundamentos que orientam a proposta de escrita de memórias de aula neste trabalho encontram ampla ressonância nos pressupostos apontados por Holly ${ }^{11}$ para a escrita de diários biográficos, destacando-se alguns aspectos em comum, como desconforto, distanciamento, transformação de perspectivas, atenção focalizada e voz. Escrever sobre si, sobre o seu trabalho, implica certo grau de exposição, o que, para muitos, gera desconforto. Tal sensação cresce à medida que o sujeito vai penetrando no seu trabalho, desnudando inconsistências, identificando incoerências, as quais vão se avolumando no papel, à espera de interpretação, de resposta, de atitude, de mudança.

A escrita de diários também provoca dois tipos de distanciamento da experiência: ao mesmo tempo em que permite explorar o significado da experiência cotidiana de um ponto de vista mais pessoal e biográfico, permite recuar espacial e temporalmente, mirando-a desde pontos de vista mais latos e menos pessoais. Esses dois tipos de distanciamento, afirma Holly, favorecem a identificação de outras dimensões de uma dada situação, o reconhecimento de determinados problemas, a interrogação sobre outras possibilidades de aceitá-los, compreendê-los ou, até, de resolvê-los. Enfim, contribui para "tomar consciência das lentes que usamos e do espírito com que nos movemos" (Holly, 2000, p.105). 
Outra característica identificada nos processos de escrita de diários biográficos é a transformação de perspectivas, que ocorre em diferentes graus entre os autores, mas em geral é provocada por acontecimentos marcantes - os dilemas referidos por Zabalza - perante os quais o sujeito já não encontra alternativa de solução, requerendo, assim, outras formas de olhar, compreender e dar sentido. Produzir outros sentidos implica reexaminar pressupostos acerca de si, dos outros e das relações pedagógicas, requer tempo e sistematicidade de reflexão. Daí a quarta característica dos diários biográficos ser a atenção focalizada, posto que contribui para superar a aplicação de 'estruturas de simplificação’ sobre os acontecimentos da sala de aula, dirigindo a atenção com mais intencionalidade, observando aspectos que lhe pareçam mais relevantes, sistematizando dados e informações que auxiliem a compreender determinada situação para além da emergência cotidiana.

Por fim, esclarece a autora, a escrita de diários pode dar visibilidade à voz do professor, na medida em que ele aprenda a interpretar a sua vida e o seu trabalho, assim como pode dar visibilidade à voz de outros, uma vez que o professor dialogue com a 'multidão íntima' que o habita. Ademais, a escrita do diário documenta a experiência de cada um para posterior análise, constituindo "uma base de discussão e de colaboração com outras pessoas" (Holly, 2000, p.108).

Durante o estágio, muitas situações exigem do professorando tomada de decisão, flexibilização de seu planejamento, soluções emergenciais para problemas imprevistos. Selecionamos, nos registros da acadêmica cujo processo formativo está sendo aqui acompanhado, três longos trechos de memórias produzidos em diferentes momentos do estágio, o qual durou cerca de 10 semanas, com três períodos semanais de 50 minutos. O primeiro trecho (Mem-1) é representativo das duas primeiras semanas de estágio; o segundo trecho (Mem-2) foi escrito pela metade do estágio; o terceiro trecho (Mem-3) é concernente às últimas aulas do estágio.

Em cada trecho selecionamos alguns recortes (identificados por letra e numeração crescente, R1, R2, R3...) que consideramos mais relevantes para os propósitos de análise do estudo. Optamos por manter o trecho com o mínimo de recortes, de modo que o leitor consiga visualizar a reflexão em seu conjunto. $\mathrm{Na}$ sequência de cada trecho, apresentamos a análise dos recortes selecionados. 
Ao entrar na sala, acompanhada da coordenadora da escola, que lembrou os alunos de que eu trabalharia com eles num período de pouco mais de um mês, senti o peso daquela responsabilidade.

(R1) Mesmo sabendo que não seguirei essa profissão, algo que decidi muito antes de iniciar o estágio, ao olhar para cada uma daquelas pessoas, eu pensei que deveria dar aquela aula como eu esperava que tivesse na idade daquelas meninas e meninos. Voltei no tempo... Lembro que eu queria mesmo era me divertir, aprender podia fazer parte disso.

(R2) Então, iniciei com uma dinâmica de apresentação dos colegas, o que não deu muito certo. Descobri que existem algumas meninas na sala que não se dão com outras, que os meninos são agitados, e ficam o tempo todo conversando. Definitivamente aquilo não deu certo. Alguns mentiam o nome e idade só pra fazer graça. Então decido me apresentar, todos silenciaram, estavam curiosos. Vi que meu erro foi não ter feito isso primeiro para que eles se acalmassem.

(R3) Falei do meu compromisso com eles, que pretendia dar uma aula como eu mesma não tinha tido, divertida, espontânea, mas que haveria regras, para que ao final deste caminho, eles soubessem tudo sobre o processo da Independência do Brasil, assunto que trabalharei com eles.

(R4) Com o mapa no centro da sala, pedi que todos levantassem, isso também não deu certo. Alguns - os mais interessados - procuraram os países que trabalharíamos conforme a atividade solicitada. Outros ficavam nas cadeiras, em seus lugares, conversando. Aquilo foi me desanimando. Por que eles não queriam participar? O que eu devia fazer para a aula tornar-se atrativa para eles? Eu comecei a ficar perdida, mas, ao mesmo tempo instigada com aqueles alunos. Eles de certa forma, me preocuparam. E a aula neste dia seguiu, de forma que enquanto eu explicava e fazia questionamentos a eles, alguns demonstravam interesse, outros nem sabiam do que eu estava falando, pelos olhares que trocavam, pelos gestos que faziam, estavam inquietos.

(R5) Ao final da aula, descobri que nem todos os pensamentos positivos e preparações teóricas eram suficientes. Alguma coisa deveria ser feita, eu queria chamar toda a turma para gostar de História junto comigo. Fui para meu trabalho animada com o desafio. Apesar de a turma não ter sido muito participativa, eles me deram um novo desafio: juntar aqueles grupinhos separados e fazê-los, em conjunto, gostar de História, entender a importância do conteúdo. Porém, também fiquei 
frustrada, toda preparação das atividades em grupo que tinha programado tinha ido por água abaixo, não adianta, eles não gostam de fazer nada em grupo.

(R6) No dia seguinte tinha um período. Pensei em não juntá-los mais para as atividades. Entreguei umas cópias em colorido de imagens de escravos em duas situações: sendo transportados em navios negreiros e em atividades de trabalho. Como não levei para todos, alguns tinham que se emprestarem as figuras, vi que eles se interessaram, talvez pelo colorido, ou pelo que eu estava explicando, pois ilustrava nas imagens. Sei que vi eles conversarem entre si: "nossa, coitados dos negros". Alguns debatiam sobre isso: "Eu acho que eles deveriam sofrer bastante". E assim consegui seguir este período.

(R7) Notei que a participação se tornou mais geral enquanto eles trabalhavam de forma individual do que em grupos, ou na forma de círculo, como no primeiro momento da primeira aula ... Naquele dia, terminei a aula numa pilha de nervos, não tinha dado uma aula boa, os alunos nem sequer sabiam o que tinham feito e para piorar, na saída da sala duas alunas brigaram. O motivo: uma tinha falado mal da outra.

(R8) Tentei novamente fazer aquela reflexão de sempre, de tentar voltar no tempo, imaginar o que eu pensaria naquela situação. Afinal, é claro que tinha vontade de rir do motivo da briga, mas não podia fazer isso na frente das meninas, que estavam achando tudo aquilo um caso serí́ssimo de inimizade. Fechei a porta da sala e pedi que todos entrassem. Para finalizar, tive uma conversa séria com todos eles. Tentei ao máximo não fazer nenhum discurso moralista. Mas aos olhos deles, pode ser que tenha parecido isso. Minha intenção era fazê-los compreender que isso era normal, que logo elas já estariam bem novamente, e que isso poderia acontecer, e vai, em todos os lugares, pois encontraremos pessoas que criam afinidades, e pessoas que criam antipatia... Os meninos somente concordavam, e diziam que isso era normal entre as duas meninas em questão. Então liberei todos para o recreio, e pedi que aquilo não se repetisse na minha aula.

(R9) Só pensava em como eu sou inexperiente. Fui para o trabalho muito chateada e assim passei o meu dia. Afinal, isso só mudaria quanto mais e mais aulas eu desse, só assim eu poderia adquirir essa experiência, em saber lidar com situações inesperadas. Aquela teoria que aprendi nos livros, somente me serviu de norte, pois percebi que cada aluno é diferente, logo, cada turma também deve ser. Assim, com os livros temos o "como fazer", na prática o "faça-o" depende de várias circunstâncias. O desafio para mim está lançado, e por sinal será complicado. 
(R10) Para as próximas aulas sei que terei ainda muito que aprender, mas de certo modo, essas primeiras experiências já foram bem significativas. (Mem-1)

Os primeiros registros de memória dessa professoranda são, em geral, marcados por uma profusão de sentimentos, que poderiam ser sintetizados em três expressões utilizadas recorrentemente: ânimo, desânimo e desafio. Ao verbalizar sentimentos tão contraditórios que se sucedem de uma aula para outra ou nos diferentes momentos de uma mesma aula, a professoranda está tentando se apropriar dos acontecimentos intensos que vivencia nas aulas, para entendê-los em sua dinâmica veloz e fugaz. As pequenas conquistas (que lhe dão ânimo) e as supostas derrotas (que lhe trazem desânimo) nas aulas acabam sempre culminando na palavra desafio, o que se pode visualizar em R4, R5 e R9, especialmente.

No que diz respeito ao uso de estratégias para compreender as situações de aula, encontramos em R1, R2 e R9 o esforço de se colocar no lugar do aluno, posição de alteridade que, nos estudos bakhtinianos, significa "assumir o horizonte concreto desse outro, tal como ele o vive". ${ }^{12}$ Ao buscar na memória o seu tempo de escola, faz o duplo movimento de tentar reconhecer as expectativas dos seus alunos adolescentes, como também renega determinadas práticas docentes, ao afirmar: "pretendia dar uma aula como eu mesma não tinha tido, divertida, espontânea” (R3). Essa prática supostamente divertida e espontânea, no entanto, não seria concretizada sem o cumprimento de determinadas regras, cuja presença garantiria, possivelmente, a aprendizagem dos alunos. Esse é um dilema muito próprio da iniciação à docência, consubstanciado no desejo de estabelecer a relação pedagógica em outras bases, que não aquelas vivenciadas na condição de aluna; desejo de fazer diferente, sem saber exatamente como isso pode ser concretizado.

Outra estratégia manifestada nos registros da estagiária se refere à identificação do que não deu certo na aula - a dinâmica da apresentação, a atividade em grupo, o trabalho com o mapa no centro da sala - e do que deu bom resultado - a disposição dos alunos em círculo, as tarefas individuais e a atividade de análise de imagens. Reconhecer o sentido de tais experiências permite traçar novas estratégias para as aulas subsequentes, o que lhe dá certo fôlego e coragem para prosseguir, tal como evidencia em R6 e R7, por exemplo. 
No penúltimo recorte desse trecho (em R9) a estagiária esboça uma tentativa de reportar-se aos referenciais teóricos apropriados na graduação, cotejando-os com as situações práticas do estágio. Trata-se de uma inserção ainda incipiente na tarefa de refletir sobre a "transferência do aprendizado", definida por Bransford, Brown e Cocking (2007, p.77) como "a capacidade de estender o que se aprende em um contexto a novos contextos", considerada "como um processo ativo e dinâmico, mais do que um produto final passivo de um conjunto específico de experiências de aprendizagem" (p.79), que exige dos aprendentes que "escolham e avaliem estratégias, considerem recursos e recebam feedback" (p.94). Lamentando a pouca experiência, a professoranda aparentemente atribui a esta a garantia de sucesso para enfrentar as emergências da sala de aula, ao afirmar: "isso só mudaria quanto mais e mais aulas eu desse, só assim eu poderia adquirir essa experiência, em saber lidar com situações inesperadas".

Na sequência da reflexão, avança no entendimento do papel que o aporte teórico ocupa na sua formação: "Aquela teoria que aprendi nos livros, somente me serviu de norte". E finaliza reconhecendo que são muitas as circunstâncias implicadas num contexto de aula. Essa é uma inferência muito próxima à que faz Gómez, quando afirma que "na prática não existem problemas, mas situações problemáticas, que se apresentam frequentemente como casos únicos, que não se enquadram nas categorias genéricas identificadas pela técnica e pela teoria existentes". ${ }^{13}$

$\mathrm{O}$ trecho que analisaremos na sequência corresponde à memória escrita ao final da segunda unidade, portanto, neste momento a professoranda já contava com dois terços do tempo de estágio cumpridos, cerca de sete semanas.

Nesta unidade, (R11) mesmo na ausência de experiência necessária para comandar uma turma como a minha, eu tinha obtido uma certeza: quanto mais atividade eu desse aos alunos, mais a aula teria andamento e, dessa forma, eu prenderia a atenção dos alunos. Esse era o caminho. E me senti começando tudo do zero, de novo. Encerradas as explicações e atividades sobre a crise no sistema colonial, fui para a escola, com meus textos xerografados, atividades e conteúdo na ponta da língua.

(R12) Mas é claro que ao chegar à sala, tudo se encontrava diferente do que planejava. Todos estavam bem agitados, chovia e fazia um frio terrível. Não entendi por que naquele frio eles estavam tão agitados. Disse que tinha uma notícia ruim, e 
que todos deviam prestar bem a atenção. Falei que as notas do trabalho dado na última aula não tinham sido boas, mas que eu faria um exercício para fixar melhor aquela matéria, já que todos pareciam não ter entendido as revoltas no Brasil durante o período colonial. Levou uns 15 ou 20 minutos, mas enfim, eles se acalmaram.

(R13) Pode ser eu que eu tenha feito "tempestade em copo d'água" com as notas deles, que na verdade, nem tinham sido tão ruins. Mas encontrei uma forma de fazê-los se acalmar: assustando-os um pouquinho.

(R14) A aula se seguiu com as atividades, alguns perguntavam se valeria nota, se recuperaria o trabalho da aula passada. Eu disse que tudo que eles faziam em aula contava pontos positivos ou negativos. Percebi que assim a aula teve melhor andamento e aproveitamento.

(R15) Ao ver que estavam preocupados, tentei quebrar o gelo, fiz algumas perguntas, andei por entre as classes conversando com alguns deles, explicando a matéria. Perguntei por que estavam tão preocupados, eles me confessaram que estavam com problemas na disciplina de matemática. A professora estava sempre brigando, gritando com todos, e eles não entendiam nada da matéria. Perguntei quem era, e era justamente a minha antiga professora de matemática. Não resisti e tive que contar-lhes, ela também tinha sido minha prô, na idade deles. Reforcei que eu não era assim tão agitada como eles e que esse era o jeito de ela dar aula. Que eles deveriam respeitar e tentar entender a matéria, pois seria muito importante para os próximos anos. Um dos alunos gritou lá do fundão: "Nossa, mas aquela professora é um museu!". Todos caíram na risada, até mesmo eu, após ter dado um sermão. Mesmo a piada sobre a idade da professora tendo causado uma agitaçãozinha, eles continuaram em seus lugares, fazendo as atividades. Eu explicando a matéria, um aluno disse: "queria que a prô de matemática explicasse que nem você, prô XXXX". Aquilo foi gratificante, confesso que me emocionei um pouco. Neste dia fui ao meu trabalho mais contente, parecia enfim ter dado uma aula boa. Apesar de ter que modificar um pouco minha postura em relação às outras aulas, ter sido um tanto mais rígida, me senti com o meu papel cumprido nesta aula. (Mem-2)

Note-se que no primeiro trecho da memória, correspondente às aulas iniciais de estágio, a tônica da reflexão girou em torno das intensas emoções que o ingresso na prática docente lhe causou, especialmente pelo esforço em identificar condutas, estratégias, meios de estabelecer uma efetiva interlocução com os alunos, ou, pelo menos, de se fazer ouvir por eles. 
No trecho subsequente, embora essas preocupações ainda estejam presentes, a professoranda acrescenta como fortes ingredientes de reflexão os fatores relativos à metodologia e à avaliação. Parece ter definido duas novas estratégias para o prosseguimento do estágio relacionadas a esses fatores. Em R11 esboça uma certeza e identifica um caminho para a continuidade do trabalho. Acredita que conseguiria maior envolvimento dos alunos na medida em que trouxesse muitas (e variadas) atividades, afirmando: "quanto mais atividade eu desse aos alunos, mais a aula teria andamento e, dessa forma, eu prenderia a atenção dos alunos".

A outra estratégia diz respeito à avaliação, da qual a professoranda se utiliza para manter os alunos sob certo controle. Essa conduta é verbalizada em R13, ao afirmar: "Pode ser que eu tenha feito 'tempestade em copo d'água' com as notas deles, que na verdade, nem tinham sido tão ruins. Mas encontrei uma forma de fazê-los se acalmar: assustando-os um pouquinho”. Em R14 se pode visualizar a intenção de fazer da avaliação também um elemento motivador do envolvimento dos alunos. Ao ser questionada pelos alunos se as atividades 'valeriam nota', afirma: "tudo que eles faziam em aula contava pontos positivos ou negativos. Percebi que assim a aula teve melhor andamento e aproveitamento".

Num primeiro olhar, essa estratégia em relação à avaliação pode parecer simples recorrência aos modelos de professor que vivenciou na sua escolarização, muitos dos quais tomou como exemplos a não serem seguidos, conforme expressou em R3. Em outro estudo (Caimi, 2008) encontramos registros muito semelhantes, que denotam a inconformidade dos professorandos com a situação que encontram nas suas salas de aula: alunos desinteressados pelos conteúdos escolares, resistentes à realização de atividades que lhes demande algum esforço; turmas heterogêneas no que respeita à relação com o saber e à sua apropriação, dentre outras. Também fica evidente a expectativa (ou a nostalgia?) de encontrar o aluno idealizado, que é naturalmente motivado para aprender, que tem plena consciência da finalidade da sua presença na escola, que é curioso, questionador, investigativo, participativo, colaborativo.

Ao lançar mão de estratégias para dar conta dessa realidade não esperada e não desejada, os professorandos apostam, muitas vezes, em ações e motivações extrínsecas, tais como a ameaça de uma nota insuficiente; de uma possível reprovação; de uma sanção ou penalidade por parte da professora, da direção 
e/ou dos pais; da possibilidade de perder a estima do professor e, até mesmo, da eventualidade de um futuro profissional comprometido. Em certa medida, são estratégias apreendidas ao longo de sua própria escolarização básica, uma vez que todos nós, na condição de alunos, já vivenciamos situações disciplinadoras dessa natureza em algum momento (senão em muitos ou em todos os momentos) de nossa vida escolar.

$\mathrm{O}$ uso frequente de determinadas estratégias acaba por constituí-las como esquemas familiares, ${ }^{14}$ que desempenham função de organizadores decisivos no conhecimento de tipo privado, quer dizer, nos modos como os indivíduos mobilizam seus conhecimentos em novas situações e contextos. Inhelder e Caprona demonstram que é característica fundamental do sistema cognitivo reduzir e traduzir aquilo que o sujeito não conhece e não entende (o desconhecido e a ininteligibilidade) à forma de esquemas muito familiares, "em que as transformações são imediatamente operáveis, mentalmente ou materialmente, e em que os estados são imediatamente visualizados ou reconhecidos sem reconstituições, inferências ou planificações etc., intermediárias" (Inhelder; Caprona, 1996, p.29).

Um dos aspectos mais instigantes desse trecho de memória diz respeito ao longo relato apresentado em R15, sobre as dificuldades da turma com a professora de Matemática. Saber que uma profissional experiente, com longos anos de carreira, que fora sua professora no ensino fundamental, estava tendo tão baixa aceitação da turma, acaba por fortalecer sua condição de professora e legitimar sua estratégia de tentar conduzir uma aula diferente das que teve como aluna do ensino fundamental. Essa legitimidade se concretiza ainda mais quando um aluno declara: "queria que a prô de matemática explicasse que nem você, prô XXXX".

Ao receber tal feedback dos alunos sobre o seu trabalho, a professoranda fica mais estimulada para prosseguir, além de ganhar confiança no caminho que escolheu lá no início do estágio, de estabelecer uma boa relação com a turma, de fazê-los gostar de História, de tornar a aula 'atrativa' para os alunos, conforme manifesta em R4. Já findando a segunda parte do estágio, verbaliza o reconhecimento de que os tradicionais 'mecanismos de arbitragem'15 nas relações entre professor e alunos não funcionam mais, e o episódio com a professora de Matemática, relatado pelos alunos, mostra que "muitos 
professores não souberam encontrar novos modelos, mais justos e participados, de convivência" (Esteve, 1995, p.107).

Vejamos, por fim, um trecho da última memória, escrita imediatamente após o término das dez semanas de estágio.

(R16) Estávamos, enfim, enturmados. Boa parte dos alunos correspondia às minhas propostas durante as aulas, e àqueles que uma vez ou outra atrapalhavam a explicação, eu procurava dar a atenção que pareciam buscar. Mas é claro, que até chegar neste ponto, como toda primeira experiência, eu tive que "sofrer" um pouquinho. Nesta unidade eu já sabia como "prender" a atenção dos alunos devido a todo processo de aprendizagem que eu mesma enfrentei nas sequências anteriores, e isso me ajudou a formar um certo roteiro, uma espécie de estratégia para atuar como professora. $\mathrm{Na}$ primeira atividade desenvolvida na programação da sequência didática, a leitura da análise da pintura de Pedro Américo, O Grito do Ipiranga, houve muitas conversas, risos, perguntas. Mas percebi, ao andar por entre as classes, que os alunos se referiam à atividade, então, deixei eles se soltarem um pouco.

(R17) Deixei a imaginação sobre aquele fato, a Independência do Brasil, tomar conta. Aos poucos, alterava meu tom de voz, chamando atenção para a continuidade das atividades que se seguiram. Assim, via que a aula tinha um andamento mais divertido para eles, e o aproveitamento em relação ao conteúdo era bem melhor. Assim seguiram-se as demais leituras, análise de imagens e da charge sobre a primeira Constituição. Procurei desenvolver um diálogo aberto, com expressões mais conhecidas durante as explicações. Levei até mesmo um dicionário comigo, logo, quando nos deparávamos com palavras difíceis, pedia para que eles me chamassem, anotassem no caderno, enquanto eu anotava no quadro, para que trocássemos esta palavra por uma mais fácil, e assim, eu iniciava a frase novamente, por exemplo: "constituição" por "organização"; "confederação" por "união de estados", conforme o dicionário trazia. Ao fim da aula desta terceira unidade, lembrei-os da prova na próxima aula. Todos demonstraram muita preocupação, perguntaram o que iria cair, como eu ia perguntar, se podiam usar material, enfim, usaram até mesmo a desculpa de que, já que eu não ia continuar mais dando aula para eles, que eu desse a prova com material, como despedida. É claro que fiquei balançada, mas não dei o braço a torcer, caso contrário, todo meu esforço teria ido por água abaixo. Então no dia da prova fiz uma breve revisão no início da aula. Tirei a conclusão de que realmente estavam preocupados, ou deviam estar todos com sono, mas estavam todos muito quietos, não questionaram muito. Fiz algumas perguntas a alguns alunos, com os quais eu estava mais preocu- 
pada, faziam parte dos "bagunceiros" e, para minha certeza, não tinham estudado mesmo.

(R18) Apesar de me dar a resposta certa, o menino da "turma do fundão" respondeu de acordo com as minhas explicações, vi que respondeu sem nenhuma base de leitura nos textos que eu havia entregado para que eles estudassem. Estava ansiosa após o final da prova. Havia muitas dúvidas: será que responderam todas? Será que aprenderam o que eu ensinei? O resultado das provas seria a resposta para as minhas incertezas ... No final das contas: três alunos atingiram a nota máxima, um aluno quase atingiu, ficando com 12 pontos. Oito alunos tiraram 10 e treze alunos tiraram 8. Ou seja, alguns realmente entenderam o conteúdo, outros pareciam ter estudado, mas lembravam de algumas coisas, e outros pareciam somente ter estudado, não entendido o que trabalhamos ...

(R19) No último dia fui um pouco triste, afinal esperava um resultado melhor. Senti-me culpada pelas notas, pois eu era quem lhes tinha passado o conteúdo, concluí que talvez eu não tivesse feito isso da melhor forma ... Fizemos uma pequena festinha, com salgadinhos e refrigerante no último período da aula. Fiquei feliz, pois cada um me deu uma cartinha no fim da aula, dizendo que sentiriam saudades, que tinham aprendido muito. Isso me animou um pouco depois do resultado da prova ter me deixado preocupada.

(R20) Apesar dos pesares, saí da escola com sentimento de missão cumprida. Afinal, aprendi muito, fiz o possível para passar-lhes o que sabia. Com certeza, eles não fazem ideia do quanto foram importantes para mim, por mais que eu tenha dito isso a eles no último dia. Todas as minhas experiências, com certeza serão úteis no próximo estágio. (Mem-3)

Fica claro, neste trecho final de memória, que a estagiária viveu aqui o período de maior tranquilidade e segurança do estágio. Diversos são os indícios e vários os recortes em que se podem visualizar referências tanto à aprendizagem dos alunos como ao seu próprio aprendizado docente. Uma situação exemplar é encontrada em R16, quando afirma: "Nesta unidade eu já sabia como 'prender' a atenção dos alunos devido a todo processo de aprendizagem que eu mesmo enfrentei nas sequências anteriores, e isso me ajudou a formar um certo roteiro, uma espécie de estratégia para atuar como professora”. Esse e outros registros evidenciam que a professora assume uma atitude investigadora, em que revisa suas suposições, questiona como os alunos compreenderam aquilo que procurou ensinar, descobre e traz à consciência as melhores estratégias para o trabalho 
neste contexto, mostrando sua própria disponibilidade para a aprendizagem. Concretiza, assim, diversas estratégias metacognitivas, na medida em que exerce uma importante capacidade apontada por Bransford, Brown e Cocking, a de "identificar os limites do conhecimento que se tem no momento, e então tomar providências para remediar a situação" (2007, p.71).

Uma vez superados os problemas interacionais mais emergentes que dizem respeito à organização da classe, ao estabelecimento de determinadas rotinas, à antecipação de ações frente a algumas situações-problema, a professoranda consegue voltar-se para questões mais centrais do trabalho docente. Por questões centrais entenda-se especificamente a atenção com os modos de ensinar história e com a aprendizagem dos alunos que, afinal, é o propósito fundamental de qualquer disciplina escolar.

\section{CONSIDERAÇÕES FINAIS}

Recuperando um pouco as análises anteriores, no intuito de concluir o texto, localizamos no primeiro trecho uma escrita permeada por muitos sentimentos contraditórios, expressos em palavras como frustrada, instigada, animada, desafiada, desanimada e chateada. Trata-se de um período inicial do estágio em que todo o esforço está voltado para garantir a 'sobrevivência'16 naquele complexo e desconhecido universo, em que o professor se vê diante de um grupo de alunos, com todas as responsabilidades que essa tarefa impõe, e precisa encontrar estratégias diante de concretas e/ou possíveis resistências para desempenhar seu papel e nele obter êxito. Nas palavras de Michael Humerman, essa lógica da sobrevivência se expressa em ações como

O tactear constante, a preocupação consigo próprio ('Estou-me a aguentar?'), a distância entre os ideais e as realidades quotidianas da sala de aula, a fragmentação do trabalho, a dificuldade em fazer face, simultaneamente, à relação pedagógica e à transmissão de conhecimentos, a oscilação entre relações demasiado íntimas e demasiado distantes, dificuldades com alunos que criam problemas, com material didáctico inadequado etc. (Huberman, 2000, p.39)

No segundo trecho o foco volta-se para aspectos metodológicos e avaliativos, com o intuito de exercer adequadamente a 'gestão da classe', entendida 
como um "conjunto de regras e de disposições necessárias para criar e manter um ambiente favorável tanto ao ensino quanto à aprendizagem" (Gauthier et al., 1998, p.240). Trata-se de uma atividade fundamentalmente cognitiva (mas permeada por muitas emoções), que requer dos professores a antecipação dos possíveis rumos da aula e a definição e consecução de regras e procedimentos, por exemplo.

Ao escrever o terceiro trecho, bem mais ambientada na dinâmica da sala de aula, a professoranda revela condições de refletir sobre a aprendizagem dos alunos, sobre as reações e os resultados que manifestam diante das suas intervenções. Nesse momento do estágio, já consegue revelar a preocupação com a 'gestão da matéria', definida por Gauthier et al. (1998, p.196) como “o conjunto de operações de que o mestre lança mão para levar os alunos a aprenderem o conteúdo". Tal definição remete-nos particularmente aos dados de planejamento, objetivos, conteúdos, estratégias de ensino, organização do trabalho pedagógico, avaliação etc.

O que se procurou demonstrar, fundamentalmente, é que o desempenho competente de professorandos inexperientes, em situação de estágio curricular supervisionado, está muito mais relacionado à 'competência adaptativa', no sentido de exercer uma prática deliberada e um monitoramento ativo das suas experiências de aprendizagem (Bransford; Brown; Cocking, 2007, p.85), do que ao resultado em si da sua intervenção docente sobre os estudantes. O recurso de escrever memórias de aula, tal como vem sendo adotado nos processos formativos em situação de estágio que acompanhamos, tem se mostrado bastante promissor para evidenciar as estratégias metacognitivas dos professorandos em sua aprendizagem profissional. Esse registro escrito da aula, entendido também como um empreendimento cognitivo, cumpre a função de objetivar suas impressões, sentimentos e percepções, de informar o próprio sujeito sobre o ponto em que se encontra na atividade, de auxiliar na identificação das suas dificuldades e dos progressos que já fez, potencializando sobremaneira suas estratégias metacognitivas e competências adaptativas.

Essa externalização do trabalho mental, como estratégia de apropriação do fazer docente, segundo contribuição de Jerome Bruner, "produz um registro de nossos esforços mentais, um registro que fica fora de nós e não vagamente na memória", ${ }^{17}$ e, na mesma medida, "resgata a atividade cognitiva do 
implícito, tornando-o mais público, negociável e solidário" (Bruner, 2001, p.32), criando condições de possibilidade para a reflexão e metacognição.

Os processos de formação profissional docente precisam oportunizar não só a prática em situação real de trabalho como se faz nos estágios supervisionados, mas especialmente garantir estratégias de reflexão, de produção de conhecimentos de natureza pedagógica e de tomada de consciência sobre as condições da docência. A prática, desacompanhada de uma criteriosa observação e análise de si mesma à luz de quadros teóricos e de valores educativos internalizados, possui um efeito formativo bastante limitado.

Nesse sentido, podemos dizer que 10 anos de carreira docente, por exemplo, não são o mesmo que 10 anos de experiência. Isso porque o professor pode exercer seus 10 anos de carreira replicando uma mesma experiência, sem tomar seu trabalho como objeto de investigação e reflexão contínua. Dez anos de experiência significam refazer cotidianamente sua prática, debruçar-se sobre os dados da sua experiência para organizá-los, refletir sobre eles e coordená-los, transformando-os em conhecimentos profissionais que possibilitem $\mathrm{o}$ redimensionamento da ação e a implementação de novas ações, qualitativamente superiores.

\section{NOTAS}

${ }^{1}$ Dentre muitos autores que se dedicam a estudos dessa natureza, podem-se destacar BRANSFORD, John D.; BROWN, Ann L.; COCKING, Rodney R. (Org.). Como as pessoas aprendem: cérebro, mente, experiência. São Paulo: Ed. Senac São Paulo, 2007; GAUTHIER, Clermont et al. Por uma teoria da pedagogia: pesquisas contemporâneas sobre o fazer docente. Ijuí (RS): Unijuí, 1998; POZO, Juan Ignácio. Aprendizes e mestres: a nova cultura da aprendizagem. Porto Alegre: Artmed, 2002; TARDIF, Maurice. Saberes docentes e formação profissional. 2.ed. Petrópolis (RJ): Vozes, 2002.

${ }^{2}$ A literatura educacional apresenta diferentes expressões para denominar a condição dos sujeitos que se encontram na transição entre ser aluno e tornar-se professor, tais como practicum (SCHÖN, D. Formar professores como profissionais reflexivos. In: NÓVOA, António (Coord.). Os professores e a sua formação. 2.ed. Lisboa: Nova Enciclopédia, 1995. p.77-90), aluno-mestre (ZEICHNER, Kenneth M. A formação reflexiva de professores: ideias e práticas. Lisboa: Educa, 1993), estagiário (PIMENTA, S. G.; LIMA, M. S. L. Estágio e docência. São Paulo: Cortez, 2004), professorando (MENDES, T. M. S. Os espaços pedagógicos de construção de possibilidades na sala de aula: um olhar sobre as microinterações. Tese [Doutorado em Educação] - UFRGS. Porto Alegre, 2000). Seguiremos, neste estudo, com as denominações predominantes na literatura brasileira - estagiário e professorando 
- pendendo mais para esta última por entendê-la como portadora de uma expressão sonora (e de um efeito de sentido) que indica passagem, movimento.

${ }^{3}$ ZABALZA, M. Diários de aula. Contributo para o estudo dos dilemas práticos dos professores. Porto: Porto Ed., 1994.

${ }^{4}$ A memória é aqui entendida como um registro sistemático e reflexivo sobre a ação docente. Na sequência do texto, será devidamente tematizada.

${ }^{5}$ Pode-se referir, a título de exemplo, TARDIF, 2002; NÓVOA (Coord.), 1995.

${ }^{6}$ HERNÁNDEZ, F. A importância de saber como as pessoas aprendem. Pátio, Porto Alegre, n.4, p.8-13, fev.-abr. 1998.

${ }^{7}$ FÁVERO, M. H.; MACHADO, C. M. C. A tomada de consciência e a prática de ensino: uma questão para a psicologia escolar. Psicologia: reflexão e crítica, v.16, n.1, p.15-28, 2003.

${ }^{8}$ FÁVERO, M. H. Psicologia e conhecimento: subsídios da psicologia do desenvolvimento para a análise de ensinar e aprender. Brasília: Ed. UnB, 2005.

${ }^{9}$ FIGUEIRA, Ana Paula C. Metacognição e seus contornos. Revista Iberoamericana de Educación, Universidade de Coimbra, Portugal, 2011, p.14. Disponível em: www.campus-oei.org/revista/deloslectores/446Couceiro.pdf; Acesso em: 26 abr. 2011.

${ }^{10}$ CAIMI, Flávia Eloisa. Aprendendo a ser professor de História. Passo Fundo (RS): Ed. UPF, 2008. p.61.

${ }^{11}$ HOLLY, M. L. Investigando a vida profissional dos professores: diários biográficos. In: NÓVOA, A. (Org.). Vidas de professores. 2.ed. Porto: Porto Ed., 2000. p.79-110.

12 BAKHTIN, Mikhail. Estética da criação verbal. 3.ed. São Paulo: Martins Fontes, 2000. p.45.

${ }^{13}$ GÓMEZ, A. P. O pensamento prático do professor. In: NÓVOA, António (Coord.), 1995. p.100.

${ }^{14}$ INHELDER, B.; CAPRONA, D. Rumo ao construtivismo psicológico. Estruturas? Procedimentos? Os dois 'indissociáveis'. In: . et al. O desenrolar das descobertas da criança: um estudo sobre as microgêneses cognitivas. Porto Alegre: Artes Médicas, 1996. p.7-37; BODER, A. 'Esquema familiar': a unidade cognitiva procedural preferida. In: INHELDER; CAPRONA, 1996. p.186-205.

${ }^{15}$ ESTEVE, J. M. Mudanças sociais e função docente. In: NÓVOA, A. (Org.). Profissão professor. 2.ed. Porto: Porto Ed., 1995. p.107.

${ }^{16}$ HUBERMAN, Michael. O ciclo de vida profissional dos professores. In: NÓVOA (Org.), 2000.

${ }^{17}$ BRUNER, Jerome. A cultura da educação. Porto Alegre: Artes Médicas, 2001. p.31.

Artigo recebido em 20 de dezembro de 2012. Aprovado em 14 de abril de 2013. 